\title{
Studi Eksperimental Kemampuan Pelepasan Panas pada Radiator Straight Fin Jenis Flat Tube dengan Variasi Cooling Liquid
}

\author{
Nuzul Hidayat $^{1^{*}}$ M Yasep Setiawan ${ }^{1}$ dan Ahmad Arif ${ }^{1}$ \\ ${ }^{1}$ Jurusan Teknik Otomotif, Fakultas Teknik, Universitas Negeri Padang \\ *Corresponding author, e-mail: nuzulhidayat@ft.unp.ac.id
}

\begin{abstract}
Abstrak - Perkembangan radiator saat ini sangat pesat baik secara kontruksi, material pembuatnya serta dimensinya yang cenderung lebih efisien dan efektif dalam pelepasan panas. Disisi lain dunia otomotif telah melakukan pengembangkan teknologi tentang cairan pendingin (cooling liquid) yang baik dalam pelepasan panas serta mampu bertahan ditemperatur tinggi. Cairan pendingin saat ini juga dikembangkan dengan memiliki kelebihan dibanding air biasa yakninya dilengkapi dengan anti-freeze agar cairan tidak membeku saat musim dingin, juga dilengkapi dengan kandungan anti karat agar radiator memiliki masa pakai yang lebih panjang. Untuk itu perlu upaya untuk mengetahui kemampuan radiator secara jelas agar ini dapat membantu dalam pemilihan jenis cairan pendingin yang cocok pada sebuah mobil sehingga mesin tidak mengalami overheating atau mesin tetap menjaga temperatur kerjanya. Hal ini berdampak pada jumlah varian cairan pendingin yang ada dipasaran sangat bervariasi dengan keunggulan masing. Metode yang digunakan dalam penelitian ini adalah dengan menggunakan metode eksperimental dengan meggunakan engine stand. Pengujian dilakukan pada radiator kijang $5 \mathrm{~K}$ model straight fin dengan model flat tube dengan menvariasikan merk dari cairan pendingin (coolant liquid) dengan 5 varian Top 1 (TP), Wurth (WR), Prestone (PT), Megacool (MC), GForce (GF). Dari hasil penelitian didapat efektifitas radiator terbaik terdapat pada cairan pendingin dengan merk PT dengan nilai 0.494 pada durasi 60 detik.
\end{abstract}

Kata Kunci : Overheating, radiator, coolant liquid, efektivitas

\begin{abstract}
The development of radiators at this time is very rapid both in construction, material maker and dimensions that tend to be more efficient and effective in heat release. On the other hand the automotive world has developed technology about cooling liquid (cooling liquid) that is good in heat dissipation and is able to survive in high temperatures. The current liquid cooling is also developed by having advantages compared to ordinary water, it is sure to be equipped with anti-freeze so that the liquid does not freeze during winter, also equipped with anti-rust content so that the radiator has a longer service life. For that we need an effort to know the radiator's ability clearly so that this can help in choosing the right type of coolant in a car so that the engine does not experience overheating or the engine while maintaining its working temperature. This has an impact on the number of cooling fluid variants on the market that varies greatly with their respective advantages. The method used in this research is to use an experimental method using the engine stand. Tests were carried out on the straight $\mathrm{K}$ model 5K deer radiator with flat tube models by varying the brand of coolant liquid with 5 variants of Top 1 (TP), Wurth (WR), Prestone (PT), Megacool (MC), G- Force (GF). From the results of the research, the effectiveness of the best radiator is found in the coolant under the PT brand with a value of 0.494 in the duration of 60 seconds
\end{abstract}

Keywords : Overheating, radiator, coolant liquid, effectiveness

This is an open access article distributed under the Creative Commons 4.0 Attribution License 


\section{Pendahuluan}

Saat ini untuk cairan pendingin pada radiator banyak dijual di pasaran dengan berbagai jenis dan berbagai komposisi diantaranya merk Preston, Master Premixed Green, Radiator Coolant Megacool dan lain-lain. Masyarakat awam tidak mendapatkan pedoman dalam pengunaan cairan pendingin mana yang cocok dengan kendaraan mereka. Hal ini penting untuk diketahui agar masyarakat bisa membeli cairan pendingin sesuai dengan karakter kendaraannya.

Dalam peningkatan efektifitas radiator banyak usaha yang dilakukan. [1]Penelitiannya tentang menvariasikan tipe radiator dan putaran mesin serta memberikan perlakuan yang sama terhadap benda uji. Hasil penelitian menunjukan bahwa dari semua variasi kecepatan udara pendinginan jenis radiator yang memiliki kemampuan pelepasan panas yang baik adalah tipe flat tube dengan nilai efektifitas 0.593 dengan variasi kecepatan aliran $3.52 \mathrm{~m} / \mathrm{s}$ dan waktu selama 120s. Dapat disimpulkan dari penelitian adalah radiator tipe flat tube memiliki pelepasan panas lebih baik dari tipe circular cylinder tube. Kemudian penelitian tentang[2] pengujian radiator dilakukan pada sirip radiator Toyota Kijang 5K dengan model straight fin jenis flat tube dengan memvariasikan sudut serang dari tube pada radiator. Dengan mengubah sudut serang maka luasan permukaan sentuh pipa menjadi lebih luas sehingga proses pembuangan panas lebih cepat dan lebih baik, kondisi ini terdapat pada posisi tube radiator dengan sudut tabung $5^{0}$ dibandingkan dengan posisi standar.

Penelitian tentang pengunaan cairan pendingin ini pernah dilakukan menggunakan mobil Mitsubishi Colt L300 Pick-up tahun 2003. Adapun sampel cairan pendingin (coolant) yang digunakan yaitu air, Mitsubishi Long Life Coolant, TOP1 Super Coolant, dan Prestone. Pengujian efektivitas dilakukan pada putaran konstan $1500 \mathrm{rpm}$ dan dalam waktu 5 menit, 10 menit dan 15 menit. Hasil penelitian menunjukkan bahwa penggunaan coolant yang memiliki titik didih yang lebih tinggi daripada titik didih air berpengaruh signifikan terhadap efektivitas radiator engine diesel. Nilai efektivitas radiator pada penggunaan Mitsubishi LLC 0, 1943 atau lebih tinggi 0, 0094 (5, 08\%). Nilai efektivitas radiator pada penggunaan TOP1 SC 0, 1965 atau lebih tinggi $0,0116(6,27 \%)$. Sedangkan nilai efektivitas radiator pada penggunaan Prestone 0, 2001 atau lebih tinggi 0, $0152(8,22 \%)$ dibandingkan dengan efektivitas radiator pada penggunaan air sebagai coolant [3].
Penelitian yang dilakukan [4] tentang variasi cairan pendingin pada sepeda motor berbahan bakar bensin. Berdasarkan hasil pengamatan, analisa data dan serta pembahasan diketahui pada fluida $100 \%$ RC Power coolant didapat nilai efektifitasnya 0,512 pada kipas standar. Pada variasi kipas single besar sebesar 0,528 , nilai efektifitas tersebut naik sebesar $3,1 \%$. Sedangkan pada double kipas memiliki nilai efektifitas 0,539, nilai efektifitas tersebut naik sebesar 2\%. Maka dapat disimpulkan bahwa semakin besar kipas yang digunakan,maka semakin naik pula nilai efektifitasnya.

Hal ini dikarenakan penumbukan angin yang semakin banyak sehingga penyerapan panas pada radiator menjadi lebih cepat. Sedangkan pada variasi fluida, pada double kipas dengan fluida $100 \%$ RC Megacools didapat nilai 0,477. Pada fluida 50\% RC Power coolant $+50 \%$ RC Megacools didapat sebesar 0,502, nilai efektifitas tersebut naik sebesar 5,2\%. Sedangkan pada fluida $100 \%$ RC Powercoolant memiliki nilai efektifitas 0,539 , nilai efektifitas tersebut naik sebesar 7,3\%. Maka dapat disimpulkan bahwa fluida dengan 100\% RC Power coolant merupakan fluida terbaik nilai efektifitasnya karena fluida100\% RC Power coolant memiliki titik didih lebih tinggi dari pada variasi fluida lainnya karena mengandung ethylene glycol.

Dari beberapa penelitian di atas dapat disimpulkan bahwa radiator berfungsi sebagai alat penukar panas yang akan mempengaruhi performa mesin. Oleh karena itu peneliti mencoba melakukan penelitian dengan membandingkan cairan pendingin (coolant liquid) radiator straight fin jenis flat tube dengan tujuan agar mendapatkan efektivitas radiator yang paling baik terhadap merk cairan pendingin. Dalam penggunaan jenis radiator radiator straight fin jenis flat tube dengan dasar karena jenis ini adalah jenis standar dari pabrik yang sudah satu unit dengan mesin tanpa modifikasi dan perubahan kontruksi.

Radiator berfungsi untuk mendinginkan cairan pendingin yang telah panas setelah melalui saluran water jacket. Cairan pendingin masuk ke tangki air bagian atas melalui selang atas. Pada tangki air bagian atas dilengkapi dengan lubang pengisian air dan saluran kecil yang menuju ke tangki cadangan. Pada tangki air bagian bawah dilengkapi dengan lubang penguras untuk mengeluarkan air pendingin pada saat mengganti cairan pendingin. Inti radiator terdiri atas pipa-pipa (tube) yang dapat dilalui air dari tangki atas ke tangki bawah. Disamping itu juga dilengkapi dengan sirip-sirip pendingin (fin) 
yang fungsinya untuk menyerap panas dari air pendingin. Biasanya radiator terletak di depan kendaraan sehingga radiator dapat didinginkan oleh gerakan kenadaraan tersebut.

Ada dua tipe inti radiator yang perbedaannya tergantung bentuk sirip-sirip pendinginnya, yaitu tipe plat (flat fin type) dan tipe lekukan (corrugated fin type) seperti terlihat pada gambar 1

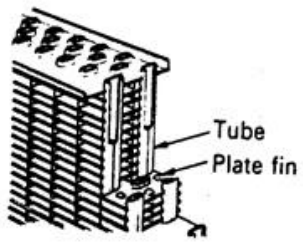

a. Tipe plat

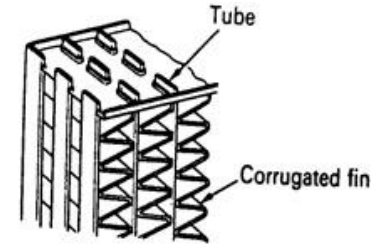

b. Tipe lekukan
Gambar 1. Radiator jenis flat tube

Air pendingin mempunyai pengaruh yang cukup besar terhadap efisiensi total engine serta umur engine. Apabila temperatur air pendingin masuk engine terlalu tinggi, maka efisiensi mekanis engine akan menurun dan dikhawatirkan dapat terjadi overheating pada engine. Sedang bila temperatur air terlalu rendah, maka efisiensi termal akan menurun [5]. Proses pendinginan melibatkan pemindahan panas dari satu substansi ke substansi yang lain. Substansi yang kehilangan panas disebut cooled, dan yang menerima panas disebut coolant. Coolant adalah cairan pendingin radiator atau air radiator berfungsi untuk menaikan titik didih air radiator mesin atau menjaga suhu kerja mesin supaya tetap ideal dan menghindari overheating pada mesin.

Syarat untuk radiator coolant yang bagus adalah

1. Tidak mengakibatkan karat atau korosi pada radiator serta tidak merusak seal di dalamnya seperti karet thermostat, karet tutup radiator,karet upper tank dan karet lower tank radiator serta water pump atau pompa air mesin mobil agar tidak mengakibatkan kebocoran water pump.

2. Tidak meninggalkan kerak atau kotoran pada komponen logam yang ada pada sistem pendinginan yang bisa membuat tersumbat saluran air, terutama saluran air pada radiator.

3. Radiator coolant harus memiliki titik didih yang tinggi lebih dari titik didih air agar air radiator tidak mudah menguap lewat reservoir, sehingga fungsi pendinginan menjadi maksimal.

4. Tidak menimbulkan buih atau busa yang membuat banyak udara terjebak didalam sistem pendingin sehingga mengurangi kemampuan pendinginan mesin.

Dilapangan beredar banyak jenis cairan pendingin radiator (cooling liquid) dengan berbagai keunggulan masing-masing. Diantaranya yang ditambahkan bahan antifreeze, anti korosi, dan tambahan bahan-bahan kimia yang membuat kemampuan cairan pendingin ini mampu mempertahankan performa dari mesin saat dioperasikan. Kondisi ini baru sebatas narasi-narasi dari produsen semata, kondisi ini perlu dibuktikan dengan melakukan percobaan dengan menguji cairan pendingin tersebut kemesin mobil dan melakukan perbandingan terhadap masing-,asing merk.

Perpindahan panas adalah transisi energi dalam bentuk panas karena adanya perbedaan suhu/temperature gradient. Secara alami perpindahan panas terjadi ke arah suhu yang rendah dan apabila semakin besar temperature gradient maka semakin besar panas yang dipindahkan. Perpindahan panas berlangsung dengan beberapa cara seperti:

\section{Perpindahan panas secara konduksi}

Perpindahan kalor secara konduksi adalah proses perpindahan kalor dimana kalor mengalir dari daerah yang bertemperatur tinggi ke daerah yang bertemperatur rendah dalam suatu medium (padat, cair atau gas) atau antara medium-medium yang berlainan yang bersinggungan secara langsung sehingga terjadi pertukaran energi dan momentum. Laju perpindahan panas yang terjadi pada perpindahan panas konduksi adalah berbanding dengan gradien suhu normal sesuai dengan persamaan berikut

Persamaan dasar konduksi adalah

$q=-k A \frac{\partial \mathrm{T}}{\partial x}$

dimana

$q=$ laju perpindahan panas $(\mathrm{kj} / \mathrm{det}$ atau watt)

$k=$ konduktivitas panas material $(\mathrm{W} / \mathrm{mK})$

$A=$ luas bidang perpindahan panas $\left(\mathrm{m}^{2}\right)$

$\partial \mathrm{T}=$ Perbedaan temperatur $(\mathrm{K})$

$\partial \mathrm{x}=$ Perbedaan jarak $(\mathrm{m})$

$d T / d x=$ gradient temperatur kearah perpindahan kalor.konstanta positif " $k$ " disebut konduktifitas atau kehantaran termal benda itu, sedangkan tanda minus disisipkan agar memenuhi hokum kedua termodinamika, yaitu bahwa kalor mengalir ketempat yang lebih rendah dalam skala temperature [6].

\section{Perpindahan panas secara konveksi}

Konveksi adalah perpindahan panas karena adanya gerakan/aliran/ pencampuran dari bagian panas ke bagian yang dingin. Contohnya adalah 
kehilangan panas dari radiator mobil, pendinginan dari secangkir kopi dll. Menurut cara menggerakkan alirannya, perpindahan panas konveksi diklasifikasikan menjadi dua, yakni konveksi bebas (free convection) dan konveksi paksa (forced convection). Bila gerakan fluida disebabkan karena adanya perbedaan kerapatan karena perbedaan suhu, maka perpindahan panasnya disebut sebagai konveksi bebas (free / natural convection). Bila gerakan fluida disebabkan oleh gaya pemaksa/eksitasi dari luar, misalkan dengan pompa atau kipas yang menggerakkan fluida sehingga fluida mengalir di atas permukaan, maka perpindahan panasnya disebut sebagai konveksi paksa (forced convection).

Laju perpindahan panas pada beda suhu tertentu dapat dihitung dengan persamaan

$q=-h A\left(T_{w}-T_{\infty}\right)$

dimana

$q \quad=$ Laju perpindahan panas $(\mathrm{kj} / \mathrm{det}$ atau $\mathrm{W})$ $h=$ Koefisien perpindahan panas konveksi $\left(\mathrm{W} / \mathrm{m}^{2}\right.$ $\mathrm{K}$ )

$A=$ Luas bidang permukaan perpindahaan panas $\left(\mathrm{m}^{2}\right)$

$T_{w} \quad=$ Temperature dinding $(\mathrm{k})$

$T_{\infty}=$ temperature sekeliling $(\mathrm{K})$

Tanda minus (-) digunakan untuk memenuhi hukum II thermodinamika, sedangkan panas yang dipindahkan selalu mempunyai tanda positif (+). Persamaan (2.2) mendefinisikan tahanan panas terhadap konveksi. Koefisien pindah panas permukaan $h$, bukanlah suatu sifat zat, akan tetapi menyatakan besarnya laju pindah panas di daerah dekat pada permukaan itu.

Konveksi paksa (force convection)

Konveksi paksa adalah perpindahan panas yang mana dialirannya tersebut berasal dari luar, seperti dari blower atau kran dan pompa. Konveksi paksa dalam pipa merupakan persolaan perpindahan konveksi untuk aliran dalam atau yang disebut dengan internal flow. Adapun aliran yang terjadi dalam pipa adalah fluida yang dibatasi oleh suatu permukaan. Sehingga lapisan batas tidak dapat berkembang secara bebas seperti halnya pada aliran luar. Sebagai gambaran adalah fenomena perpindahan panas aliran di dalam pipa yang dinyatakan sebagai:

$q=\dot{m} c_{p} \Delta T_{b}$

\section{Perpindahanpanas secara radiasi}

Perpindahan panas radiasi adalah proses dimana panas mengalir dari benda yang bersuhu tinggi ke benda yang bersuhu rendah bila benda-benda itu terpisah di dalam ruang, bahkan jika terdapat ruang hampa di antara benda - benda tersebut. Energi radiasi dikeluarkan oleh benda karena temperatur, yang dipindahkan melalui ruang antara, dalam bentuk gelombang elektromagnetik bila energi radiasi menimpa suatu bahan, maka sebagian radiasi dipantulkan, sebagian diserap dan sebagian diteruskan. Untuk menentukan besarnya energi adalah

$\left.q^{\prime \prime}=\varepsilon \sigma T_{s}^{4}\right)$

dimana

$q^{\prime \prime}=$ laju perpindahan panas $(\mathrm{W})$

$\sigma=$ konstanta boltzman $(5,669.10-8 \mathrm{~W} / \mathrm{m} 2 . \mathrm{K} 4)$

$\varepsilon=$ emissivity $(0<\varepsilon<1)$

$T_{S}=$ suhu absolut benda $\left({ }^{0} \mathrm{C}\right)$

Alat Penukar Panas (Heat Exchanger)

Alat penukar panas (heat exchanger) adalah suatu alat yang digunakan untuk memindahkan panas antara dua buah fluida atau lebih yang memiliki perbedaan temperatur yaitu fluida yang bertemperatur tinggi ke fluida yang bertemperatur rendah. Perpindahan panas tersebut baik secara langsung maupun secara tidak langsung. Pada kebanyakan sistem kedua fluida ini tidak mengalami kontak langsung. Kontak langsung alat penukar kalor terjadi sebagai contoh pada gas kalor yang terfluidisasi dalam cairan dingin untuk meningkatkan temperatur cairan atau mendinginkan gas.

Alat penukar panas yang digunakan pada kendaraan dapat kita jumpai pada radiator yang fungsinya pada dasarnya adalah sebagai alat penukar panas. Radiator adalah alat penukar panas yang digunakan untuk memindahkan energi panas dari satu medium ke medium lainnya yang tujuannya untuk mendinginkan maupun memanaskan. Radiator yang kita kenal pada umumnya digunakan pada kendaraan bermotor (roda dua atau roda empat), namun tidak jarang radiator juga digunakan pada mesin yang memerlukan pendinginan ekstra. Seperti pada mesin mesin produksi atau mesin mesin lainnya yang bekerja dalam kondisi kerja berat atau lama. Pada kendaraan baik motor atau mobil radiator pada umumnya terletak di depan dan berada didekat mesin atau pada posisi tertentu yang menguntungkan bagi system pendinginan. Hal ini bertujuan agar mesin mendapatkan pendinginan yang maksimal sesuai yang dibutuhkan mesin. Radiator terdiri dari tangki air bagian atas (upper tank), tangki bagian bawah (lower water tank) dan radiator core pada bagian tengahnya.

Panas yang dibuang oleh cairan pendingin dapat dihitung dengan menggunakan persamaan yaitu $q=\dot{m} c_{p} \Delta T$ 
$q=\dot{m} c_{p} T_{2}-T_{1}$

(2.6)

dimana

$q \quad=$ laju perpindahan panas ( $\mathrm{kJ} /$ det atau $\mathrm{W}$ )

$m=$ massa laju aliran cairan pendingin $(\mathrm{kg} / \mathrm{s})$

$c_{p} \quad=$ kapasitas panas masuk $(\mathrm{J} / \mathrm{kgK})$

$T_{1}=$ Temperatur masuk $(\mathrm{K})$

$T_{2}=$ Temperatur keluar $(\mathrm{K})$

Dari persamaan tersebut maka kita bisa dapat menganalisis perpindahan panas pada sebuah radiator sebagai berikut (Holman.J.P, 1988 ):

Jumlah panas yang dilepaskan oleh air

$q_{a}=\dot{m}_{a} c_{p} T_{a 1}-T_{a 2}$

dimana

$q_{a}=$ laju perpindahan panas yang dilepas air ( $\mathrm{kJ} /$ det atau W )

$m_{a}=$ massa laju air yang mengalir $(\mathrm{kg} / \mathrm{s})$

$c_{p}=$ kapasitas panas masuk $(\mathrm{J} / \mathrm{kgK})$

$T_{a 1}=$ Temperatur air masuk $(\mathrm{K})$

$T_{a 2}=$ Temperatur air keluar $(\mathrm{K})$

Sedangkan untuk menghitung massa air yang mengalir dapat menggunakan persamaan

$\dot{m}_{a}=\rho_{a} V_{a} A$

dimana

$\rho_{a}=$ massa jenis air $\left(\mathrm{kg} / \mathrm{m}^{3}\right)$

$V_{a}=$ kecepatan air masuk $(\mathrm{m} / \mathrm{s})$

$A=$ luas penampang saluran masuk $\left(\mathrm{m}^{2}\right)$

Jumlah panas oleh udara pendingin

$$
\begin{aligned}
& q_{u}=\dot{m}_{u} c_{p} T_{u 2}-T_{u 1} \\
& \text { dimana }
\end{aligned}
$$

$q_{u}=$ Laju perpindahan panas yang diterima udara pendingin (Watt)

$\dot{m}_{u}=$ massa laju aliran udara yang mengalir $(\mathrm{kg} / \mathrm{s})$

$c_{p}=$ kapasitas panas masuk $(\mathrm{J} / \mathrm{kgK})$

$T_{u 1}=$ Temperatur udara keluar $(\mathrm{K})$

$T_{u 2}=$ Temperatur udara masuk $(\mathrm{K})$

Sedangkan untuk menghitung massa udara yang mengalir dapat menggunakan persamaan adalah

$\dot{m}_{u}=\rho_{u} V_{u} A$

dimana

$\rho_{u}=$ massa jenis udara $\left(\mathrm{kg} / \mathrm{m}^{3}\right)$

$V_{u}=$ kecepatan udara masuk $(\mathrm{m} / \mathrm{s})$

$A=$ luas penampang saluran masuk udara

Efektivitas penukar panas didefinisikan sebagai perbandingan antara laju perpindahan kalor yang sebenarnya dengan laju perpindahan kalor maksimum yang mungkin. Dimana persamaannya dapat ditunjukan seperti berikut ini:

$\varepsilon=\frac{q}{q_{\max }}$

dimana

$q=$ perpindahan panas nyata $(\mathrm{W})$

$q_{\text {max }}=$ perpindahan panas maksimum yang mungkin (W)
Untuk perpindahan panas yang sebenarnya (aktual) dapat dihitung dari energi yang dilepaskan oleh fluida panas atau energi yang diterima oleh fluida dingin untuk penukar panas aliran lawan arah.

$q=\dot{m}_{h} c_{h}\left(T_{h, \text { in }}-T_{h, \text { out }}\right)=\dot{m}_{c} c_{c}\left(T_{c, \text { out }}-T_{c, \text { in }}\right)$

$$
\text { (2.12) }
$$

Dimana:

$\dot{m}_{h}=$ laju aliran fluida panas $(\mathrm{kg} / \mathrm{s})$

$\dot{m}_{c}=$ laju aliran fluida dingin $(\mathrm{kg} / \mathrm{s})$

$c_{h}=$ kapasitas panas fluida panas $(\mathrm{Kj} / \mathrm{kg} \mathrm{K})$

$c_{c}=$ kapasitas panas fluida dingin $(\mathrm{Kj} / \mathrm{kgK})$

$T_{h, \text { in }}=$ Temperatur masuk fluida panas $(\mathrm{K})$

$T_{h, \text { out }}=$ Temperatur keluar fluida panas $(\mathrm{K})$

$T_{c, i n}=$ Temperatur masuk fluida dingin (K)

$T_{c, \text { out }}=$ Temperatur keluar fluida dingin (K)

Kapasitas panas setiap fluida dapat dicari melalui persamaan:

$C=\dot{m} \quad c_{p}$

Dimana:

$\dot{m}=$ laju aliran fluida $(\mathrm{kg} / \mathrm{s})$

$c_{p}=$ panas spesifik fluida $(\mathrm{Kj} / \mathrm{kg} \mathrm{K})$

Untuk menentukan perpindahan panas maksimum bagi penukar panas itu harus dipahami bahwa nilai maksimum akan didapat bila salah satu fluida mengalami perubahan temperatur sebesar beda temperatur maksimum yang terdapat dalam penukar panas itu, yaitu selisih temperatur masuk fluida panas dan fluida dingin. Fluida yang mungkin mengalami beda temperatur maksimum ini ialah yang laju aliran fluida dinginnya minimum, syarat keseimbangan energi bahwa energi yang diterima oleh fluida yang satu harus sama dengan energi yang dilepas oleh fluida yang lain. Jika fluida yang mengalami nilai laju alitan fluida dingannya lebih besar yang dibuat, maka mengalami beda temperatur yang lebih besar dari maksimum, dan ini tidak dimungkinkan. Jadi perpindahan panas maksimum yang mungkin dinyatakan sebagai

$q_{\max }=\dot{m} c_{\min }\left(T_{h, \text { in }}-T_{c, \text { in }}\right)$

dimana, $c_{\min }$ merupakan kapasitas panas yang terkecil antara fluida dingin dan fluida panas. Jika $c_{h}=c_{\min }$ maka nilai efektivitas dapat dicari dengan persamaan berikut:

$$
\begin{aligned}
& \varepsilon=\frac{\dot{m}_{h} c_{h}\left(T_{h, \text { in }}-T_{h, \text { out }}\right)}{\dot{m} c_{m i n}\left(T_{h, \text { in }}-T_{c, \text { in }}\right)} \\
& \varepsilon=\frac{\left(T_{h, \text { in }}-T_{h, \text { out }}\right)}{\left(T_{h, \text { in }}-T_{c, \text { in }}\right)}
\end{aligned}
$$

Sedangkan untuk $c_{c}=c_{\min }$, nilai efektivitas dapat dicari dengan persamaan berikut

$\varepsilon=\frac{\dot{m}_{c} c_{c}\left(T_{c, \text { out }}-T_{c, \text { in }}\right)}{\dot{m} c_{\min }\left(T_{h, \text { in }}-T_{c, \text { in }}\right)}$

$\varepsilon=\frac{\left(T_{c, \text { out }}-T_{c, \text { in }}\right)}{\left(T_{h, \text { in }}-T_{c, \text { in }}\right)}$ 


\section{Metode}

Penelitian ini dilakukan dengan menggunakan metode eksperimental. Pengujian dilakukan pada engine stand mobil kijang super $5 \mathrm{~K}$ dengan model radiator straight fin jenis flat tube. Untuk memperoleh efektivitas radiator yang optimun dilakukan variasi cairan pendingin dan variasi waktu, kemudian dianalisis dengan menggunakan persamaan efektifitas $(\varepsilon)$ pada alat penukar panas dengan cara mengukur temperatur air pendingin dan udara pendingin.

Proses pemasangan radiator dan seluruh rangkaian pengujian dilakukan di Laboratorium Jurusan Teknik Otomotif Fakultas Teknik Universitas Negeri Padang.

Alat uji yang akan digunakan dalam penelitian ini antara lain sebagai berikut:

Radiator straigt fin, dengan spesifikasi:

Mesin : kijang super 5K

Model fin : straight fin

Model Tube : flat tube

Type collant : water collant

Flow type : down flow

Gambar 2 merupakan skema radiator straight fin jenis flat tube.

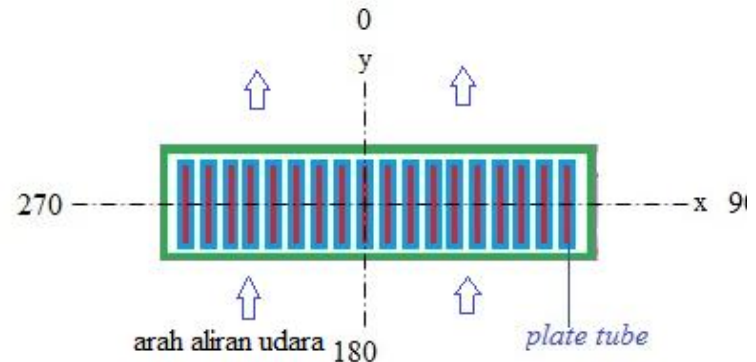

Gambar 2. Skema radiator straight fin jenis flat tube pada pandangan atas

Adapun untuk skema apparatus experimental penelitian dapat dilihat seperti gambar 3 .

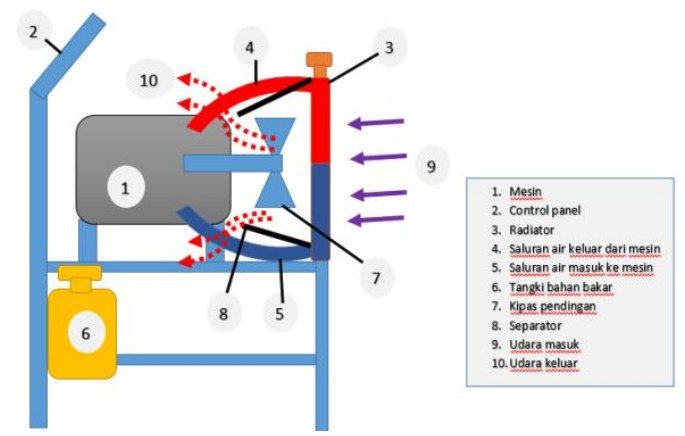

Gambar 3. Skema apparatus experimental penelitian

\section{HASIL DAN PEMBAHASAN}

Setelah melakukan penelitian ini maka didapat data temperatur pendinginan yang terjadi pada radiator dengan menggunakan thermocouple kemudian dimasukan kedalam persamaan efektifitas pelepasan panas. Dari data tersebut dapat dilihat tentang pengaruh penggunaan cairan pendingin (coolant liquid) terhadap kemampuan pelepasan panas pada radiator mobil. Variasi yang dilakukan dengan membedakan merk namun durasi pendinginan. Untuk lebih jelas dapat dilihat pada tabel 1

Tabel 1. Efektivitas cairan pendinginan merk TP

\begin{tabular}{ccccccc}
\hline $\begin{array}{c}\text { Veloci } \\
\text { ty } \\
(\mathrm{m} / \mathrm{s})\end{array}$ & $\begin{array}{c}\text { Wak } \\
\text { tu } \\
(\mathrm{s})\end{array}$ & $\begin{array}{c}\text { T udara } \\
\text { in }\left({ }^{\circ} \mathrm{C}\right)\end{array}$ & $\begin{array}{c}\text { T udara } \\
\operatorname{out}\left({ }^{\circ} \mathrm{C}\right)\end{array}$ & $\begin{array}{c}\mathrm{T} \text { air } \\
\text { in }\left({ }^{\circ} \mathrm{C}\right)\end{array}$ & $\begin{array}{c}\mathrm{T} \text { air } \\
\text { out }\left({ }^{\circ} \mathrm{C}\right)\end{array}$ & $\varepsilon$ \\
\hline & 60 & 31.80 & 42.30 & 59.60 & 48.70 & 0.378 \\
\cline { 2 - 7 } 2.04 & 120 & 31.80 & 42.70 & 60.90 & 49.90 & 0.375 \\
\cline { 2 - 7 } & 180 & 31.80 & 43.00 & 61.90 & 50.40 & 0.372 \\
\cline { 2 - 7 } & 240 & 31.80 & 42.90 & 62.20 & 50.70 & 0.365 \\
\hline 300 & 31.80 & 43.20 & 63.30 & 51.00 & 0.362 \\
\hline 360 & 31.80 & 43.00 & 63.30 & 51.40 & 0.356 \\
\hline
\end{tabular}

Tabel 1, menunjukan kecenderungan nilai efektifitas menurun dengan semakin meningkatnya durasi pengoperasian mesin kendaraan, kondisi ini dipengaruhi oleh kemampuan radiator dalam mendinginkan cairan pendingin. Nilai efektifitas paling tinggi terdapat pada durasi 60 detik yaitu 0.378 .

Tabel 2. Efektivitas cairan pendinginan merk PT

\begin{tabular}{ccccccc}
\hline $\begin{array}{c}\text { Veloci } \\
\text { ty } \\
(\mathrm{m} / \mathrm{s})\end{array}$ & $\begin{array}{c}\text { Wak } \\
\text { tu } \\
(\mathrm{s})\end{array}$ & $\begin{array}{c}\mathrm{T} \text { udara } \\
\text { in }\left({ }^{\circ} \mathrm{C}\right)\end{array}$ & $\begin{array}{c}\text { T udara } \\
\text { out }\left({ }^{\circ} \mathrm{C}\right)\end{array}$ & $\begin{array}{c}\mathrm{T} \text { air } \\
\text { in }\left({ }^{\circ} \mathrm{C}\right)\end{array}$ & $\begin{array}{c}\text { T air } \\
\text { out }\left({ }^{\circ} \mathrm{C}\right)\end{array}$ & $\varepsilon$ \\
\hline & 60 & 31.80 & 48.00 & 64.60 & 55.20 & 0.494 \\
\cline { 2 - 7 } 2.04 & 120 & 31.80 & 48.20 & 65.10 & 55.60 & 0.492 \\
\cline { 2 - 7 } & 180 & 31.80 & 48.40 & 65.80 & 56.10 & 0.488 \\
\cline { 2 - 7 } & 240 & 31.80 & 48.50 & 66.10 & 56.20 & 0.487 \\
\hline & 300 & 31.80 & 48.90 & 67.20 & 56.20 & 0.483 \\
\hline
\end{tabular}

Dari tabel 2 diatas kecendrungan nilai efektivitas radiator juga sama dengan TP yaitu semakin lama durasi semakin menurun efektifitas radiator. Untuk nilai efektifitas secara keseluruhan lebih baik dari TP yaitu dengan nilai efektifitas paling baik terjadi pada durasi 60 detik dengan nialai efektifitas 0.494. Efektifitas terendah terdapat pada durasi 360 detik yaitu sebesar 0.475 . 
Tabel 3. Efektivitas cairan pendinginan merk Wurth

\begin{tabular}{ccccccc}
\hline $\begin{array}{c}\text { Veloci } \\
\text { ty } \\
(\mathrm{m} / \mathrm{s})\end{array}$ & $\begin{array}{c}\text { Wak } \\
\text { tu } \\
(\mathrm{s})\end{array}$ & $\begin{array}{c}\text { T udara } \\
\text { in }\left({ }^{0} \mathrm{C}\right)\end{array}$ & $\begin{array}{c}\text { T udara } \\
\text { out }\left({ }^{0} \mathrm{C}\right)\end{array}$ & $\begin{array}{c}\text { T air } \\
\text { in }\left({ }^{\circ} \mathrm{C}\right)\end{array}$ & $\begin{array}{c}\text { T air } \\
\text { out }\left({ }^{\circ} \mathrm{C}\right)\end{array}$ & $\varepsilon$ \\
\hline & 60 & 31.40 & 47.10 & 63.60 & 53.60 & 0.488 \\
\cline { 2 - 7 } 2.04 & 120 & 31.40 & 47.20 & 64.80 & 53.20 & 0.473 \\
\cline { 2 - 7 } & 180 & 31.40 & 47.30 & 65.10 & 53.40 & 0.472 \\
\cline { 2 - 7 } & 240 & 31.40 & 47.40 & 65.50 & 54.00 & 0.469 \\
\hline & 300 & 31.40 & 47.50 & 65.90 & 54.00 & 0.467 \\
\hline & 360 & 31.40 & 47.00 & 66.20 & 54.50 & 0.448 \\
\hline
\end{tabular}

Dari tabel 3 kecendrungan nilai efektifitas WR lebih rendah dari PT yaitu nilai efektifitas tertinggi terdapat pada durasi 60 detik yaitu 0.488 dan terendah terdapat pada durasi 360 detik yaitu 0.448 .

Tabel 4. Efektivitas cairan pendinginan merk GForce

\begin{tabular}{ccccccc}
\hline $\begin{array}{c}\text { Veloci } \\
\text { ty } \\
(\mathrm{m} / \mathrm{s})\end{array}$ & $\begin{array}{c}\text { Wak } \\
\text { tu } \\
(\mathrm{s})\end{array}$ & $\begin{array}{c}\text { T udara } \\
\text { in }\left({ }^{\circ} \mathrm{C}\right)\end{array}$ & $\begin{array}{c}\text { T udara } \\
\text { out }\left({ }^{0} \mathrm{C}\right)\end{array}$ & $\begin{array}{c}\text { T air } \\
\text { in }\left({ }^{\circ} \mathrm{C}\right)\end{array}$ & $\begin{array}{c}\text { T air } \\
\text { out }\left({ }^{\circ} \mathrm{C}\right)\end{array}$ & $\varepsilon$ \\
\hline & 60 & 29.70 & 45.70 & 64.60 & 52.70 & 0.458 \\
\cline { 2 - 7 } 2.04 & 120 & 29.70 & 45.70 & 64.80 & 53.10 & 0.456 \\
\cline { 2 - 7 } & 180 & 29.70 & 45.70 & 65.10 & 53.20 & 0.452 \\
\cline { 2 - 7 } & 240 & 29.70 & 45.60 & 65.30 & 53.60 & 0.447 \\
\hline & 300 & 29.70 & 45.40 & 65.50 & 53.70 & 0.439 \\
\hline & 360 & 29.70 & 45.20 & 65.70 & 53.90 & 0.431 \\
\hline
\end{tabular}

Dari tabel 4 nilai efektifitas tertinggi terdapat pada durasi 60 detik yaitu 0.458 dan yang terendah terdapat pada durasi 360 detik yaitu0.431.

Tabel 5. Efektivitas cairan pendinginan merk MC

\begin{tabular}{ccccccc}
\hline $\begin{array}{c}\text { Veloci } \\
\text { ty } \\
(\mathrm{m} / \mathrm{s})\end{array}$ & $\begin{array}{c}\text { Wak } \\
\text { tu } \\
(\mathrm{s})\end{array}$ & $\begin{array}{c}\text { T udara } \\
\text { in }\left({ }^{\circ} \mathrm{C}\right)\end{array}$ & $\begin{array}{c}\text { T udara } \\
\text { out }\left({ }^{0} \mathrm{C}\right)\end{array}$ & $\begin{array}{c}\text { T air } \\
\text { in }\left({ }^{\circ} \mathrm{C}\right)\end{array}$ & $\begin{array}{c}\text { T air } \\
\text { out }\left({ }^{\circ} \mathrm{C}\right)\end{array}$ & $\varepsilon$ \\
\hline & 60 & 32.00 & 46.89 & 66.90 & 54.70 & 0.427 \\
\cline { 2 - 7 } 2.04 & 120 & 32.00 & 46.70 & 67.00 & 54.90 & 0.420 \\
\cline { 2 - 7 } & 180 & 32.00 & 46.30 & 67.20 & 55.00 & 0.406 \\
\cline { 2 - 7 } & 240 & 32.00 & 45.90 & 67.20 & 55.10 & 0.395 \\
\cline { 2 - 7 } & 300 & 32.00 & 45.70 & 67.30 & 55.20 & 0.388 \\
\hline & 360 & 32.00 & 45.50 & 67.40 & 55.20 & 0.381 \\
\hline
\end{tabular}

Dari tabel 5 dapat dilihat nilai efektifitas tertinggi terdapat pada durasi 60 detik yaitu 0.427 dan yang terendah terdapat di durasi 360 detik yaitu 0.381 .
PERBANDINGAN NILAI EFEKTIFITAS

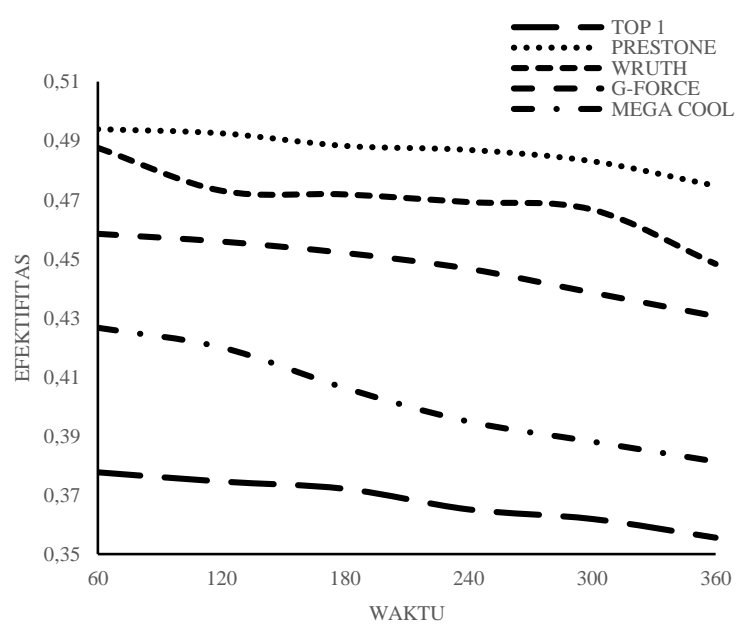

Gambar 4. Grafik Perbandingan efektifitas pada radiator dengan variasi cairan pendingin

Dari grafik gambar 4 dapat dilihat dengan 5 variasi cairan pendingin maka dapat kita lihat secara garis besar bahwa efektifitas radiator kecendrungan menurun dengan meningkatnya waktu. Nilai efektifitas radiator paling baik terjadi pada merk Prestone untuk semua variasi waktu. Setelah itu merk wurth kemudian GF, MC dan terakhir TP.

Pada merk PT mengandung Ethylene Glycol sampai 30\% yang memungkinkan cairan pendingin lebih baik dalam mereduksi panas sehingga efektifitas radiator meningkat. Kondisi ini sesuai dengan penelitian pendahuluan yang dilakukan oleh [7]. Kadungan dari Ethylene Glycol adalah menaikan titik didih dari cairan pendingin dengan menambahkan Ethylene Glycol pada cairan pendingin maka dapat membuat cairan pendingin lebih mampu menahan panas sehingga tidak mudah menguap.

\section{KESIMPULAN}

Dari penelitian yang sudah dilakukan maka dapat disimpulkan bahwa Ethylene Glycol mempengaruhi kemampuan cairan pendingin daalam mereduksi panas. Dengan kemampuan tersebut sehingga dapat meningkatkan efektifitas dari radiator. Kondisi efektifitas pada radiator terbaik terdapat pada merk PT untuk semua variasi waktu.

\section{DAfTAR PUSTAKa}

[1] N. Hidayat, T. Sugiarto, and D. Yuvenda, "Optimization of Effectiveness in Radiator 
Straight Fin Type With Flat Tube Angle Variation," no. October, pp. 13-15, 2017.

[2] N. Hidayat and A. Arif, "Perbandingan Kemampuan Pelepasan Panas Pada Alat Penukar Panas Radiator Straight Fin Jenis Circular Cylinder Tube Dengan Flat Tube," vol. 19, no. 1, 2019.

[3] L. L. Coolant, "Pengaruh Variasi Cairan Pendingin ( Coolant ) Terhadap," 2017.

[4] A. N. Gusti, "Publikasi Online Mahasiswa Teknik Mesin Analisa Pengaruh Macam Macam Fluida Dan Variasi Kipas Terhadap Efektifitas Penyerapan Panas Pada Motor Bensin 135CC," vol. 1, no. 1, pp. 1-9, 2018.

[5] Ekadewi Anggraini Handoyo, “" Pengaruh Temperatur Air Pendingin Terhadap Konsumsi Bahan Bakar Motor Diesel Stasioner di Sebuah Huller" JURNAL TEKNIK MESIN Vol. 1, No. 1, April 1999: 8 - 13.," vol. 1 , no. 1, pp. 8-13, 1999.

[6] J. P. Holman, "Heat Transer," 2009.

[7] B. N. D. Nuryanto, T. Istanto, and W. E. Juwana, "Pengaruh laju aliran coolant campuran air dengan ethylene glycol terhadap laju perpindahan panas dan penurunan tekanan radiator otomotif," $J$. Tek. Mesin Indones., vol. 11, no. 2, p. 71, 2018.

\section{Biodata Penulis}

Nuzul Hidayat, dilahirkan di Tigo Suku, 16 Januari 1987. Menyelesaikan S1 pada program studi Pendidikan Teknik Otomotif Jurusan Teknik Otomotif FT - UNP Padang tahun 2010 dan pendidikan Pascasarjana (S2) Magister Teknik di jurusan Teknik Mesin Program Pascasarjana ITS Surabaya dengan bidang konsentrasi Rekayasa Konversi Energi pada tahun 2013. Sejak tahun 2013 sampai sekarang menjadi staf pengajar di jurusan Teknik Otomotif FT - UNP.

M. Yasep Setiawan, lahir di Salimpauang, 30 September 1989. Sarjana Pendidikan di Jurusan Teknik Otomotif FT - UNP 2011. Tahun 2014 memperoleh gelar Magister Teknik di program studi Rekayasa Konversi Energi jurusan Teknik Mesin Program Pascasarjana ITS Surabaya. Staf pengajar di Jurusan Teknik Otomotif FT - UNP sejak tahun 2015 sampai sekarang

Ahmad Arif, lahir di Padang Panjang, 27 Februari 1989. Pendidikan S1 di program studi Pendidikan Teknik Otomotif jurusan Teknik Otomotif FT UNP Padang dan lulus tahun 2012. Tahun 2013 2015 melanjutkan pendidikan S2 di program studi Rekayasa Konversi Energi jurusan Teknik Mesin Program Pascasarjana ITS Surabaya. Selanjutnya menjadi staf pengajar di Jurusan Teknik Otomotif FT - UNP sejak tahun 2015 sampai sekarang. 